\title{
Addendum: Females show more sustained performance during test-taking than males
}

Pau Balart [D \& Matthijs Oosterveen

Addendum to: Nature Communications https://doi.org/10.1038/s41467-019-11691-y, published online 3 September 2019.

We would like to make readers aware that after the publication of this Article, there was an update in PISA's 2018 Technical report to the response time data used for the PISA 2015 and 2018 datasets (https:/www.oecd.org/pisa/data/pisa2018technicalreport/PISA2018-TechReportAnnex-K.pdf). The response time variable was found to represent the time spent on the last visit to a test item, rather than the total time spent on the item, as originally described by PISA and as we thought was used in the original version of this Article. 
PISA now provides data on the total time spent on an item, and we have demonstrated that the pattern of results shown in Figure $4 \mathrm{a}$ in the Original Article does not change when using the time variable of total time spent on the item (Fig. 1).

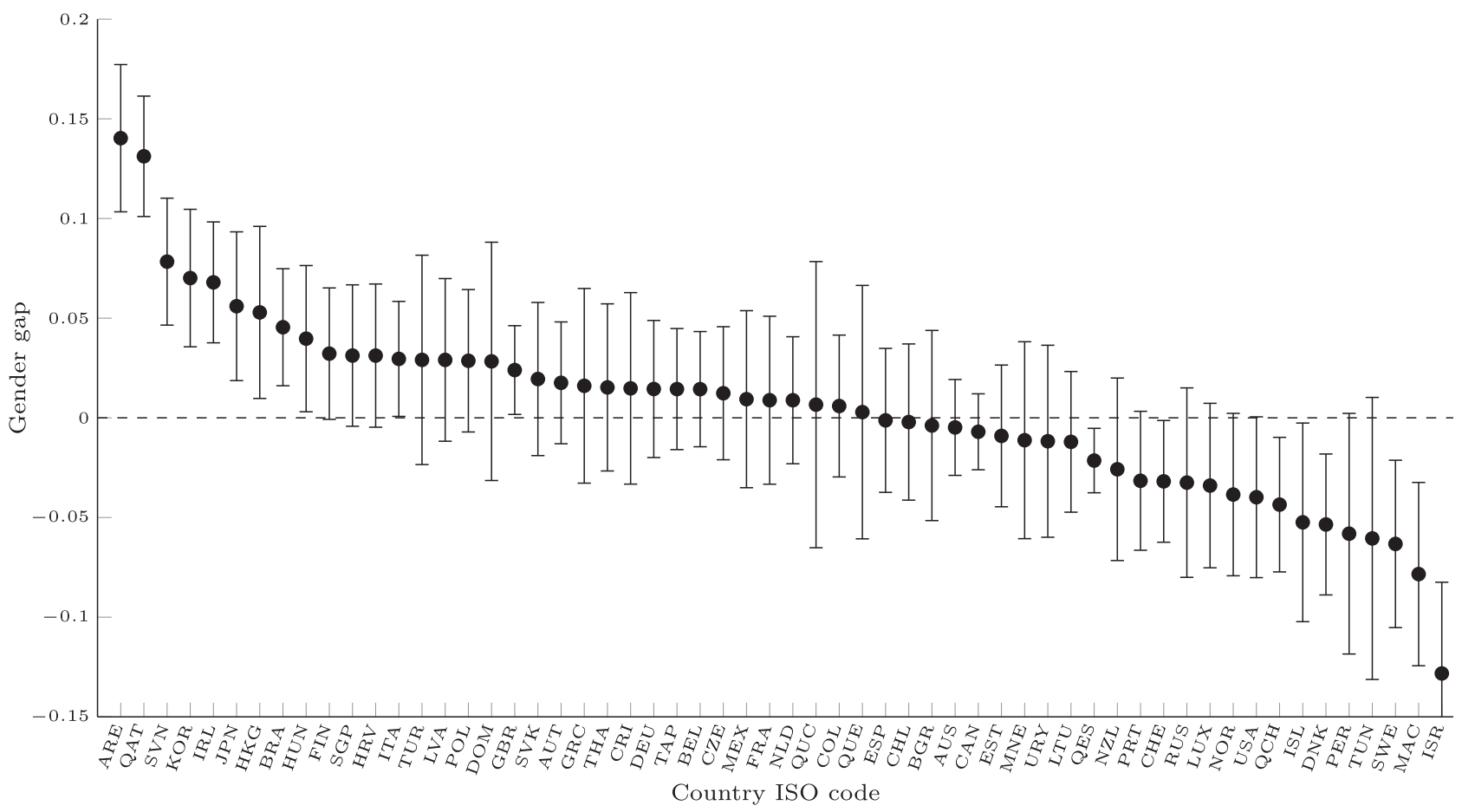

Published online: 18 January 2022

(c) (i) Open Access This article is licensed under a Creative Commons Attribution 4.0 International License, which permits use, sharing, adaptation, distribution and reproduction in any medium or format, as long as you give appropriate credit to the original author(s) and the source, provide a link to the Creative Commons license, and indicate if changes were made. The images or other third party material in this article are included in the article's Creative Commons license, unless indicated otherwise in a credit line to the material. If material is not included in the article's Creative Commons license and your intended use is not permitted by statutory regulation or exceeds the permitted use, you will need to obtain permission directly from the copyright holder. To view a copy of this license, visit http://creativecommons.org/licenses/by/4.0/.

(C) The Author(s) 2022 